\title{
Article
}

\section{A qualitative study of parents' experiences using family support services: applying the concept of surface and depth}

Whittaker, Karen, Cox, Pat, Thomas, Nigel and Cocker, Karen

Available at http://clok.uclan.ac.uk/12605/

Whittaker, Karen ORCID: 0000-0002-3493-9396, Cox, Pat ORCID: 0000-00032565-4564, Thomas, Nigel ORCID: 0000-0002-5310-9144 and Cocker, Karen (2014) A qualitative study of parents' experiences using family support services: applying the concept of surface and depth. Health and Social Care in the Community, 22 (5). pp. 479-487. ISSN 0966-0410

It is advisable to refer to the publisher's version if you intend to cite from the work. http://dx.doi.org/10.1111/hsc. 12101

For more information about UCLan's research in this area go to http://www.uclan.ac.uk/researchgroups/ and search for <name of research Group>.

For information about Research generally at UCLan please go to http://www.uclan.ac.uk/research/

All outputs in CLoK are protected by Intellectual Property Rights law, including Copyright law. Copyright, IPR and Moral Rights for the works on this site are retained by the individual authors and/or other copyright owners. Terms and conditions for use of this material are defined in the policies page.

\section{CLoK}

Central Lancashire online Knowledge www.clok.uclan.ac.uk

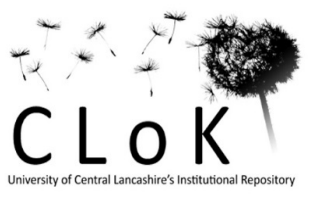




\section{Pre-publication copy.}

\section{Cite as:}

Whittaker, K. A., Cox, P., Thomas, N., \& Cocker, K. (2014). A qualitative study of parents' experiences using family support services: applying the concept of surface and depth. Health $\&$ Social Care in the Community, 22(5), 479-487. DOI: 10.1111/hsc.12101

This is the peer reviewed version of the following article: Whittaker, K. A., Cox, P., Thomas, N., \& Cocker, K. (2014). A qualitative study of parents' experiences using family support services: applying the concept of surface and depth. Health \& Social Care in the Community, 22(5), 479-487. DOI: 10.1111/hsc.12101, which has been published in final form at: http://onlinelibrary.wiley.com/doi/10.1111/hsc.12101/abstract. This article may be used for non-commercial purposes in accordance with Wiley Terms and Conditions for Self-Archiving."

\section{Abstract}

UK policy and practice endorses family support for child well-being. Achieving such support requires multi-agency approaches, that consider all aspects of parents' and children's lives and which offer practical, social and emotional help. The potential for services to make a positive impact on parents and their families will depend in part on the level and nature of engagement. In this paper a case is made for the application of the two-part 'surface and depth' concept for understanding how practitioners engage with families and how they might improve the chances of supporting sustainable differences for parents and families. To illustrate, qualitative data from a review of family centre support provided by a north of England local authority, are presented. The review was commissioned to explore why families often need to re-engage with intensive support services. Data are drawn from interviews with parents $(n=18$, recruited following a survey of all those registered with the service during April - May 2009) and discussions with family centre support workers $(n=4)$ and following thematic analysis three dominant themes emerged: 'resources available', 'staff approach' and 'real life', were appraised in light of the 'surface and depth' concept. Much of the work with parents effectively dealt with pressing needs. This felt gratifying for both parent and worker and supported immediate service engagement. However, each noted that 
the more complex issues in parents' lives went unchallenged and thus the sustainability of progress in terms of parenting practice was questionable. A 'strengths focused' approach by

staff, that understood needs in the context of parents' 'real life' circumstances was important to parent engagement. Thus, longer term benefits from family support requires practitioners to work with parents to problem solve immediate issues whilst also digging deeper to acknowledge and seek to resolve the more complex challenges parents face in their real lives.

\section{What is known about this topic}

- When parents make positive changes following access to support services, the need for recurring family support can remain.

- Limited parental engagement with services is identified as a key reason for intervention failure.

\section{What this paper adds}

- If support focuses in the main on practical help and does not extend deep enough to help parent address relationship issues, their need to re-engage with services in the future should not be unexpected.

- The surface and depth concept adds value not only to our data analysis, but also to relationship-based work in practice settings and has implications for how health and social care practitioners are educated to understand and undertake their roles. 


\section{Introduction}

This paper reports a northern England qualitative study exploring parents' experiences of engaging with centre-based family support practitioners, designated to provide additional and intensive support. The research was prompted by a local authority's concern that some families persistently re-engaged with intensive support services. Therefore through this study we explored parents' perspectives of parent-practitioner contacts. In order to ensure that the exploration of this contact was rigorous and learning was transferable to practice settings, we drew on Howe's (1996) two-part concept of 'surface and depth', previously applied to social work practice and which, we argue, is pertinent to a wider health and social care context. In this paper we will outline the concept of 'surface and depth' and it's relevance for family support. This will be followed by a description of the study and analysis of findings, concluding with recommendations for practice.

Working with families in complex situations is challenging. Addressing the associated complexities of poverty, health inequalities and parenting in difficult social circumstances requires proven preventive interventions beginning in early childhood (Marmot 2010). These should be available on a proportionate basis, so that those with increased needs can access additional help. What is more, interventions offered should be based on well-tested theory (Department of Health [DH] 2009) which is able to explain the mechanism for change and is sufficiently understood by practitioners charged with helping parents to achieve specified objectives (Moran et al. 2004). Different forms of parenting support available can be identified by the mode of delivery and setting; with formal and informal help available for individuals, groups and families either in the home, community centres, specialist facilities or via virtual spaces supported by electronic media (Whittaker and Cowley 2012a). Centre- 
based support is often used as a key means of providing services for families with the most acute needs (Warren-Adamson 2006, Fernandez 2007). However, service availability alone does not ensure needs are met, as other contextual factors play an important part in whether parents engage sufficiently to gain benefit from parenting and family support (Axford et al. 2012, Platt 2012, Whittaker and Cowley 2012b). One point concerns gender imbalances, with mothers being the predominant users of parenting services (Garrett 2009, Whittaker and Cowley 2012a). This arguably limits the extent that issues shared by mothers and fathers can be comprehensively addressed. What is more, the sustainability of positive changes following family support interventions is often unknown (Moran et al. 2004, Moran 2009) and the need for recurring support can be common (Gardner 2003).

Theoretical principles identified as advantageous to parenting support interventions include social learning and attachment theories, found in both group- and home-based interventions (Barlow et al. 2008). Ecological theory is helpful for strengthening the design of comprehensive programmes of support (Moran et al. 2004) as it explains the reciprocal interrelated factors impacting on parenting (Bronfenbrenner 2005). However, evidence indicates that it is the approach taken by the practitioner that will be of particular value and perhaps even critical for engaging parents and reaching mutual agreements about which interventions best meet identified needs (Barnes 2003). Arguably, strengths perspectives are important in this regard, given that they start the relationship on an optimistic footing by building upon what parents do well. When embedded in 'relationship-based' work (Davis and Day 2010), such a perspective helps to convey respect and assists the practitioner in deploying communication skills that offer 'containment' (Douglas 2007, Howe 2010) for parents in stressful circumstances. Containment, originally developed as a concept by Bion (1959), describes how the worker offers, during client interactions, an emotionally safe 
situation where the client feels contained (in the sense of being supported, rather than restricted). The trust created between practitioners and parents provides the basis for parents to 'open up' and share sensitive information (Kirkpatrick et al. 2007, McIntosh and Shute 2007). Howe (2010) summarizes the worth of such relationships in enabling parents to achieve supportive engagement with their children; Kemp et al. (2011) demonstrate the positive influences on child outcomes; Olds et al. (2007) demonstrate that better outcomes are achieved when workers are more qualified.

In addressing the inadequate use of theory and knowledge in social work practice, Howe (1996) proposed the two-part concept of 'surface and depth'. Both parts can serve particular purposes depending on the practitioner and their knowledge and skills. 'Surface' is explained as an approach taken when practitioners endeavour to use a 'present tense' approach when working with service users and carers (clients), assisting them to address current issues in their lives and relationships. This approach is not underpinned by knowledge or learning and little attention is paid to the quality of the worker-client interaction. For the practitioner and the agency this offers a functional mode of engaging individual families that speedily addresses presenting problems and frees the practitioners up to take on the next client waiting, thus supporting service efficiency. Arguably it leads to practitioners proposing solutions insufficiently grounded in any wider theoretical reasoning, creating short-term options that mainly respond to the consequences of deeper issues, rather than the issues themselves. In comparison, a 'depth' approach is underpinned by deployment of theoretical knowledge to understand the client's account of her own life. This emphasises a focus on the whole person and eschews practice where clients are labeled and slotted into pre-defined descriptive categories, for example, 'abused mother' as opposed to 'mother who has survived serious abuse and who is successfully raising her own children'. This offers scope to engage 
with the deep issues that, if neglected, give rise to the sorts of difficulties that families often struggle to resolve without intervention and support. The engagement by the practitioner is purposeful and informed by relevant theory, such as psychological or sociological theory, in order to move beyond presenting issues and reach the causes of difficulties. In his presentation of the two-part concept of surface and depth, Howe (1996) views depth as a positive (more helpful) approach and surface, by comparison, much less favourably. In our analysis, the two parts of Howe's concept are both seen as necessary and mutually beneficial.

From our readings of the 'surface and depth' concept, it is compatible with a number of theories and principles that are currently taught and practised within health and social care. For example, the theory of human ecology (Bronfenbrenner 2005) and the principle of working within a strengths-based model (Pattoni 2012) are both compatible. Ecological theory explains layers of influence in society that are nested like 'Russian dolls' and that support ripple effects passing either way. That is, the outer community-level activity has effects that ripple down to the family and individual, and similarly the behaviour of the individual ripples outwards, impacting on the family and community experiences. The strengths-based model is concerned with the potential within people, their knowledge, skills and capacity to act, which may in the first instance be overlooked when problems have been foregrounded. Practitioners cognisant of both would acknowledge the need to consider not just the presenting information, but also that which is seemingly hidden but equally part of what makes the experience for the individual. 


\section{Methods}

\section{Aim}

The study was prompted by a local authority concern that families often re-enter systems providing intensive family support. The aim was to examine parents' experiences, and specifically their perceptions of help available, to develop an understanding of why some families may find themselves needing to return for additional help.

\section{Setting}

The study was located within a single north of England local authority which, through five family centres, supported families (children aged 0-11 years) who had been identified as needing additional help when assessed by health and social care professionals. Locally this had been defined as circumstances where parenting was compromised and children were deemed to have high levels of need. These family centres complemented universal service provision by local Sure Start Children's Centres, by providing focused help to those with more complex difficulties, either on a one-to-one or group basis. At the family centre practitioners used the Common Assessment Framework [CAF] (DH 2000) to determine the extent of need, and designed a CAF plan to work with families to safeguard their children and address difficulties that if neglected would undermine healthy child development. The work included ongoing needs assessments, completion of planned packages of care and support with access to other services and professionals, for example drug and alcohol misuse teams and housing departments.

\section{Design}

An interpretive approach (Mason 2002) shaped the study design and choice of methods for examination of experiences of family centre support. This approach enabled us to consider 
parents' own accounts of service use and practitioner perceptions about their family support work. The proposal for this work was reviewed and approved by the local University ethics committee (FHEC No.327).

\section{Sample and data collection}

Parents ( $\mathrm{n}=116)$ registered during April and May of 2009 to access one of the five local authority family centres were provided with a study information sheet, consent form and brief questionnaire; findings from the questionnaire were reported to the funders. Parents were invited to identify the services they used and their willingness to be interviewed. Fifty-seven parents $(49 \%)$ returned the questionnaire; of these 30 provided contact details for interview participation. On follow-up, three declined interview stating a change of circumstances and nine were unavailable or did not return voicemail messages. In total 18 parents were interviewed at a family centre either in a group $(n=6)$ or individually $(n=12)$. In addition, a convenience sample of four family centre staff acted as key informants and participated in brief discussions about the services and the needs of families. This was intended to provide additional information about the service, and later helped to contextualise parents' narratives during data analysis. Prior to the interview, information about the study was explained and verbal consent was confirmed. An interview topic guide was used to explore with parents how they felt about the services they accessed and the relevance of these to their needs. Two researchers attended the group interview, allowing one to concentrate on asking questions and listening, the other observing and note-taking (Fontana \& Frey 2003). Having consulted with workers at the centres during the phase of study design, the research team was advised that interviews with parents should be conducted in the least threatening way. This was because this group of parents might be inclined to be suspicious of anyone (unknown) outside the service asking them questions about their lives and relationships (Kadushin \& Kadushin, 
1997). It was therefore agreed during negotiations for access to the research site that only note-taking would be used during data collection and that there would be no audio-recording. For individual interviews, only one researcher was involved; simultaneously asking interview questions and taking notes. This form of practice is habitual for workers based in health and social care settings and thereby parents would have been familiar with this form of recording conversations. Irrespective of this, as part of agreeing verbal consent to proceed with the interview, parents were asked permission for the researcher to record the conversation by taking notes.

\section{Data analysis}

Interview data were thematically analysed using the approach recommended by Miles and Huberman (1994), whereby after collection data are reduced, displayed and verified.

Reduction involved selective transcription of the detailed handwritten notes made during interview. Because of the small numbers, individual and group level data were triangulated and then aggregated. In order to ensure full confidentiality of staff and parents and because these centres are located in a limited geographical area and given the increasing ease of access to personal information via the online world (Tilley and Woodhouse 2011) participants were allocated numbers for reference. Extracts from participants' interviews are coded by centre and allocated participant number. For example centre 1 , participant 3 , is shown as (1.3). All centre 5 participants were interviewed as a group. When transcribed, data were coded and allocated to categories using post-it notes and flip chart paper. This was an iterative process allowing further reduction of the data until solid themes emerged across all the cases. Thematic analysis allows overlaps in data to be recognised, which fits with real world experience where events and feelings are invariably connected (Robson 2002). The 
concept of surface and depth was then used to generate a further level of interpretation of study themes and to produce transferable messages for other family support situations. The brief self-completion questionnaire enabled recording of demographic information and forms of help accessed by parents. To assist those with literacy difficulties, centre caseworkers were briefed in how to read the questions and collect responses from parents. Descriptive statistics were computed to describe the sample.

\section{Findings}

\section{Study Participants}

Of the 57 parents who responded, 18 agreed to be interviewed to explore their service experiences further. Most were white females ( $n=53,93 \%)$ aged 17-54 years (mean 30 years). Few were in paid employment $(n=3,5 \%)$; just under half lived in lone adult households $(\mathrm{n}=26,45 \%)$. Half the participants had a partner, although only a third reported living with their partner. The majority $(n=47,82 \%)$ reported that they had attended the family centre to which they had been referred. Fewer identified receiving help from other specific professionals such as social workers $(n=18,32 \%)$ or health visitors $(n=16,28 \%)$.

\section{Parent experiences}

Three main interconnected themes emerged from parents' discussions about their service experiences. These concerned the resources available, staff approach and the interaction of these features with the parents' real life. Quotations from interviews are included to illustrate themes, numbered to preserve anonymity. 


\section{Resources}

The family centre was typically identified as offering practical help and, to some extent, a social resource. For several parents, the centres were difficult to access and they cited problematic bus journeys when managing buggies for children. In spite of this, they described family centres as being friendly and comfortable. Help was largely available through access to key facilities and staff providing assistance with key skills such as making telephone calls, cooking and managing routines:

I get help with parenting skills and practical help about how to cook and do my cleaning and look after my children. We look at routines and playing with them (1.9).

They help me filling in forms and show me how to do it and help me doing it. You can make phone calls when you are here as well and they help you with that (1.4).

Parents acknowledged being able to ask for help if required and several identified that meeting other parents with whom they shared similar circumstances was particularly helpful:

You can ask for help if needed (1.1).

There is someone to talk to (5.5), to offload to (5.6).

...make new friends, you know others that know what it's like to be on your own with kids and havin, you know, them on yuh back (5.2).

The key worker here she's beltin, so it's OK here (1.2).

The first of the two extracts from parent interviews above exemplify a surface approach by staff to parents' issues: 'how to do...' In the second set of extracts where parents discuss help and help-sharing, a sense of depth with some staff and some other parents is evident. The final extract in this section highlights the importance of staff attitudes and how they define parents' experiences. 
Staff approach: The focus of staff intervention was to follow action plans derived from the original assessment of need (DH 2000). Activities mainly addressed practical tasks including baby/childcare, family routines (cooking, bathing, bedtimes) and household management (budgeting). These activities were dominated by the on-going assessment which, depending on staff approaches, could be a difficult experience for parents. Consequences of noncompliance feared by parents included re-referrals to social workers, which indeed was threatened by some staff:

They tell you what to do and threaten you with social workers and that you might lose your kids. (2.3)

I thought would they take the children away - because they had control.(2.2)

You feel like you have to please them (3.2).

Parents considered experiences to be poor when staff were 'interfering' $(1.2 ; 2.1 ; 3.2)$ and concerned with 'checking cupboards' (2.2) and reaching targets:

They are very target driven and say things like 'you need to be here', you know, pointing to a list (2.2).

Staff approaches which could be described as directive were unhelpful; characterised by being 'told what to do' $(1.2 ; 1.3 ; 2.2 ; 5.1)$, being 'observed and monitored' $(2.1 ; 1.2,5.1)$.

It can feel like your whole life is being looked into and that is daunting (1.8).

Some don't listen to you and just say what they want to say all the time and make you feel like they don't even want to know about how you feel (2.3).

The first set of interview extracts above demonstrate that making threats and engendering fear leads to behaviour being modified; however, this is not an effective basis for workerparent relationships characterised by trust. The focus on targets typifies current surface 
approaches in health and social care. 'Having your whole life looked into' is not, as first appears, a depth approach; this parent's use of 'daunting' shows how intimidated she was by the experience; not a good foundation for building relationships characterized by containment. The final extract here expresses this parent's regret that apparently no staff member will engage in depth work with her.

Parents found staff helpful when they listened to parents' perspectives, acknowledging their strengths and ability to change. Some staff used praise effectively to balance feedback; avoiding overly-criticising whilst being clear about what parents must achieve. In the extracts below, trust in the workers is evident:

They told me what I needed to hear ...they told me straight and challenged me to do better (4.1).

Makes you feel you are 'progressing' 'I'm really pleased with you' - They give you praise that's sincere. Makes you feel good, you can do it (2.2).

\section{Real life}

Several parents perceived requirements to follow professionally-driven plans characterised by directive approaches from some practitioners to approach childcare and personal relationships by 'do[ing] it this way' (5.2) '- our way, not your way' (2.2) as being less in tune with what parents believed feasible or even desirable. Parents commented that support workers would say: 'you should do this or shouldn't do that' (5.3) and explained 'it's like they're the parent telling you what to do' (1.2). One parent argued that staff 'need to understand our lives' (5.1): what it meant to be a single parent living on a particular estate, responding to their children's needs and managing relationships with ex-partners and family members:

they don't understand your life - cos how could I do what they asked me to do without people to help (5.1). 
Several parents mentioned experiences of domestic violence with previous partners who were also their children's fathers. With few material and social resources at their disposal, these women often continued sharing the same locality and social circle as their ex-partners. Parents viewed staff advice to avoid contact as unrealistic, especially when 'he's the dad' (2.1).

One parent contrasted the approaches of different staff members who she felt 'laid down the rules' (5.1) to that of another who had asked how she saw her future in relation to her expartner (father of children). The latter was felt to be a more satisfying and realistic approach by: 'you know, askin' how I see it and how did I want the relationship to go' (5.1). Directive approaches can be effective in changing behaviours, but parents on the receiving end need to feel that what is required of them is achievable in the contexts of their lives, otherwise changes are surface-style only. Advice that is not grounded in any understanding of the parents' relationships will not be followed and opportunities for depth work are missed.

\section{Practitioner perspectives}

All practitioners acknowledged the complexity of the families' lives, claiming that many had 'chaos and a lifestyle at home that is not addressed properly if they are just coming to the centre' (Practitioner 2). Practitioners questioned the transferability of skills learnt in the centre, advocating working with families in their homes and the centre to achieve more durable outcomes. Practitioners noted that parents often 'come back with the next pregnancy' (Practitioner 1) because, in our analysis, longstanding issues re-emerge. Working with parents experiencing complex social situations could be quite overwhelming for practitioners to manage; they spoke of 'wearing 10 different hats each day' (Practitioner 4) to face the multiple needs of families. 
Practitioners interviewed appeared aware of their monitoring role, believing the consequences were that sometimes parents learnt to 'perform' and 'please' them. They felt this was particularly so when the action plan included only centre attendance without regular home visits, and they articulated the limitations of surface-style work:

They come here to perform ...do all that we ask of them and then go home and do their own thing (Practitioner 2).

Support workers, who were qualified nursery nurses, had learnt about topics such as domestic violence, parenting and drugs and alcohol through attending short courses. They acknowledged that they had been trained primarily to address children's needs and they were less equipped to deal with any wider family issues. In these extracts from practitioner interviews there is acknowledgement that it is often easier to maintain worker-parent relationships at surface level, particularly if workers feel they lack education and training to engage at depth. There is also acknowledgement that depth work would achieve more lasting effects in families' lives.

\section{Discussion}

We have applied the surface and depth concept in analysing our findings, as interview data from parents reflect the need for responses which address them as individuals and (sometimes) a wish for different kinds of relationship with workers. Data from workers demonstrate that their interventions are not underpinned by theoretical knowledge of any kind $-\mathrm{a}$ 'surface' approach. It is our contention that applying this concept to the findings from both parents and workers clarifies the dissonance between parents' appreciation of the pleasant atmosphere and an almost inexpressible longing for something more. The following discussion explores the application of the concept further and considers implications for practice. 
Parents offered fairly consistent responses about receiving from family centres a friendly welcome, anticipating that helpful support would be offered; such comments highlight their worth. Activities focused on developing practical skills, facilitated mainly by support workers and to lesser degrees by social workers and health visitors. Emotional support was derived from the manner in which learning practical skills was encouraged, and as a result of feeling listened to and respected (surface approach); rather than as an outcome of a considered and 'containing' relationship (depth approach). In the main, support workers had trained as nursery nurses, a noteworthy point given that nursery nurse preparation focuses on interactions with children and childhood development, while by contrast family support roles require interactions with parents as opposed to children. Thus, family support and involvement in guiding parenting practice can for some, as acknowledged by participants here, represent a departure from the role for which they were originally prepared. By contrast, social worker and health visitor professional education focuses on holistic family practice and child and family support needs are typically addressed through direct work with parents or carers.

It was apparent that although new skills had been learnt, these were not consistently transferred and embedded into parents' lives and that parents were not achieving levels of behaviour change which would lead to sustained lifestyle changes, possibly due to an emphasis on practical tasks. These practical tasks centralized the purpose of support, engaging with immediate child developmental needs, parenting capacity and aspects of wider family and environmental factors (the three dimensions of need delineated in the Assessment Framework (DH 2000)). Practitioners were concerned that some parents may have 'performed'; similarly, parents indicated that they felt they needed to please workers. Parents 
suggested that an 'expert' model (Scott and Dadds 2009) was in operation, as they were frequently instructed what to do. This is an ineffective practice intervention, as reluctant participants often agree with advice in order to manage their image as competent parents (Peckover 2002), but then will 'do their own thing' at home (Gillies 2006, Russell and Drennan 2007).

Parents implied that they 'played the game' to survive the system whilst attending the centres, demonstrating that they are skilled and competent social beings with pre-existing strengths. Workers could have engaged in greater emotional depth and more holistically with these parents, given the repeated messages from research. For example studies by Roche $e t$ al. (2005), Davis and Day (2010) and Bidmead (2013), demonstrate parents' desires to be more actively engaged in decision-making about support services for themselves. Moreover, this would have been compatible with the ecological approach (Bronfenbrenner 2005). The workers in this study missed these opportunities, however the transferable learning is that other workers can learn from this and actively choose to engage parents differently. The consequence of not working with parents in their own homes and communities meant that it was easier for practitioners and parents in this study to choose not to engage with the complexities of parents' real lives as a 'depth' approach would require (Howe 1996); given this, these parents' need for service re-engagement is understandable.

When parents were unable to experience positive parent-practitioner relationships, engagement with the service was about 'turning up' and 'agreeing with what they were told' and requirements to explain their personal circumstances left them feeling exposed and vulnerable. As research by McIntosh and Shute (2007) and by Donetto et al. (2013) demonstrates, parents feel despondent when practitioners emphasise failings rather than successes. This, together with the 'expert' model, had tended to alienate parents. Friendliness 
and practical activities are both valuable in engaging parents; however both skills address relationships and issues in the present. The theme 'real life' shows parents distinguishing clearly between surface and depth understandings of their feelings, experiences and life contexts (Howe 1996); an example of this was the dilemma for mothers of maintaining their children's contact with former abusive partners.

Some parents' wish for greater understanding indicated a need for individually responsive services offering containment, rather than 'one size fits all'. However, building relationships of trust and containment through good communication skills requires time (Howe 2010, Bidmead 2013). Engaging in respectful communication and understanding the complexities of parents' lives are both essential for workers with families with complex needs, not least because parents may feel over-burdened when first referred to support services and unable to acknowledge the benefits of engaging (Barlow et al. 2005).

The challenge of work with people with complex lives is that they rarely have one single need; multiple needs are meshed together and responding to one need requires engaging with several others. By its nature this is 'difficult' work, and therefore families in these circumstances risk being a 'seldom-heard group' in practice (Hernandez et al. 2010) and in research (Pitts and Smith 2007). Indeed the difficulty in contacting parents as part of recruitment to this study is illustrative of some of the challenges practitioners can face in trying to work with families identified as needing intensive support. However, data such as parents feeling that practitioners could be interfering may be indicative of the fragile engagement found elsewhere between this client group and routine services (Murray et al. 2003). Moreover, workers may not see asking difficult questions about parents' stressful relationships and circumstances as being within their remit or abilities (Featherstone 2004), 
particularly if they are low-paid, untrained and quite possibly, unconfident. The challenge of the depth approach is that it requires sufficiently knowledgeable and educated practitioners who understand that by encouraging clients to share personal details (and re-live events) they are potentially opening troubling feelings and experiences which require careful and sustained responses. Data from previous evidence-based programmes indicate that such alliances are best achieved when highly qualified practitioners deliver services (Olds et al. 2007).

It is noted that the generalizability of findings from this small-scale qualitative study may be limited. Further, as in other parenting research, most participants were women and therefore this study is unable to comment on the experiences of fathers in any depth. On the other hand, consistent messages are present in the parent and practitioner data, which resonate with existing and prior work (Roche et al. 2005, Davis and Day 2010, Bidmead 2013). This suggests that these are issues of importance for those working with parents in complex circumstances. The implications for practice and education emerging from these findings include the need to design services on ecological principles to facilitate practice interventions that take account of the complexity of family and community life. Practitioners also need to be supported in adopting approaches that are relationship-based and enable parents to feel valued and respected. This could begin with the inclusion of 'surface and depth' concepts, in conjunction with ecological and strengths-based perspectives, in accredited programmes for all who work with families with complex needs.

\section{Conclusion}

The analysis of findings from this study demonstrates the potential for positive outcomes for parents in families with multiple needs if workers adopt both surface and depth approaches. 
By combining these approaches in support services, the potential strengths of each are realised. Here a surface approach evident in practitioners' action regarding parents' pressing needs for learning child-centred practical skills matched their desire for a responsive service. Where a depth approach was used, it complemented the surface approach by offering understandings of parents' real lives and containment for them in a potentially anxietyprovoking situation in the centres. Working in this way, practitioners were recognising and valuing parents' existing resources and building upon their strengths. Enhancing this strengths approach, services designed to take account of the multiple layers that make up families' lives would support practitioners in framing their work according to ecological principles. Thus, in attempting to address the local authority's concern about why parents might need to re-engage with services, combining application of surface and depth approaches with ecological approaches and strengths-based perspectives provides a means to understand and begin to address this question. 


\section{References}

Axford N., Lehtonen M., Kaoukji D., Tobin K., \& Berry V. (2012) Engaging parents in parenting programs: Lessons from research and practice. Children and Youth Services Review 34, 2061-2071. DOI:10.1016/j.childyouth.2012.06.011

Barlow J., McMillan A.S., Kirkpatrick S. \& Ghate H. (2008) Health-led Parenting: Interventions in Pregnancy and Early Years. Department for Children, Schools and Families, Nottingham UK

http://www.dcsf.gov.uk/research/programmeofresearch/projectinformation.cfm?projectid=15 $\underline{479 \& \text { resultspage }=1}$ Accessed from 24.03.2012

Barlow J., Kirkpatrick S., Stewart Brown S. \& Davis H. (2005) Hard to reach or out of reach? Reasons why women refuse to take part in early interventions. Children and Society, 19 (3), 199-2010. DOI:10.1002/chi.835

Barnes J. (2003) Interventions addressing infant mental health problems. Children and Society, 17 (5), 386-395. DOI:10.1002/chi.793

Bidmead, C. (2013). Health visitor/parent relationships: a qualitative analysis. In Cowley S., Whittaker K., Grigulis A., Malone M., Donetto S., Wood H., Morrow E. \& Maben J. (Eds.) Why Health Visiting? London: National Nursing Research Unit, King's College. http://www.kcl.ac.uk/nursing/research/nnru/publications/index.aspx Accessed from 25.03.2013

Bion W.R. (1962) Learning from Experience. Basic Books, New York USA.

Bronfenbrenner U. (2005) Making Human Beings Human: Bioecological Perspectives on Human Development 2nd edn. Sage, London UK.

Davis H. \& Day C. (2010) Working in Partnership with Parents 2nd edn. Pearson, London UK.

Department of Health (2009) Healthy Child Programme: The Two Year Review. Department of Health, London UK.

Department of Health (2000) (with Department of Education \& The Home Office) Framework for assessment of children in need and their families, Department of Health, London UK.

Donetto S., Malone M., Hughes J., Morrow E., Cowley S. \& Maben J. (2013) Health visiting: the voice of service users. Learning from service users' experiences to inform the development of UK health visiting practice and services (Department of Health Policy Research Programme, ref. 016 0058) London: National Nursing Research Unit, King's College.

http://www.kcl.ac.uk/nursing/research/nnru/publications/index.aspx Accessed from 03.10.2013 
Douglas H. (2007) Containment and Reciprocity: Integrating Psychoanalytic Theory and Child Development Research for Work with Children. Routledge, Oxford UK.

Featherstone B. (2004) Family Life and Family Support. Palgrave Macmillan, Hampshire UK.

Fernandez E. (2007) Supporting children and responding to their families: Capturing the evidence on family support. Child and Youth Services Review, 29 (10), 1368-1394. DOI:10.1016/j.childyouth.2007.05.012

Fontana A. \& Frey J. H. (2003) The Interview: From Structured Questions to Negotiated Text. In: Denzin, N. K. \& Lincoln, Y.S. (Eds) Collecting and Interpreting Qualitative Materials. (2 ${ }^{\text {nd }}$ Edn) Pages 61-106. Sage, California.

Gardner R. (2002) Supporting Families: Protecting Children in the Community. John Wiley, Chichester UK.

Garrett P.M. (2009) 'Transforming' Children's Services? Social Work, Neoliberalism and the 'Modern' World. McGraw-Hill Education and Open University Press, Berkshire UK.

Gillies V. (2006) Parenting, class and culture: Exploring the context of childrearing. Community Practitioner, 79, 114-117.

Hernandez L., Robson P. \& Sampson A. (2010) Towards integrated participation: Involving seldom heard users of social care services. British Journal of Social Work, 40 (3), 714-736. DOI:10.1093/bjsw/bcn118

Howe D. (1996) Surface and depth in social work practice. In: Parton N. (Ed) Social Theory, Social Change and Social Work. Routledge, London UK, pp. 77-97.

Howe D. (2010) The safety of children and the parent-worker relationship in cases of child abuse and neglect. Child Abuse Review, 19 (5), 330-341. DOI:10.1002/car.1136

Kadushin A. \& Kadushin G. (1997) The Social Work Interview: A Guide for Human Service Professionals $\left(4^{\text {th }}\right.$ Ed) Columbia University Press, New York.

Kemp L., Harris E., McMahon C., Matthey S., Vimpani G., Anderson T., Schmied V., Aslam H. \& Zapart S. (2011) Child and family outcomes of a long-term home nurse visitation programme: A randomized control trial. Arch. Dis. Child, 96, 533-540. DOI:10.1136/adc/2010.196279

Kirkpatrick S., Barlow J., Stewart-Brown S. \& Davis H. (2007) Working in partnership: User perceptions of intensive home visiting. Child Abuse Review, 16 (1), 32-46.

DOI:10.1002/car.972

Marmot .M. (2010) Fair Society, Healthy Lives: The Marmot Review. Institute of Health Equity, University College, London UK.

Mason J. (2002) Qualitative Researching, 2nd edn. Sage, London UK. 
McIntosh J. \& Shute J. (2007) The process of health visiting and its contribution to parental support in the Starting Well demonstration project. Health and Social Care in the Community, 15 (1), 77-85. DOI:10.1111/j.1365-2524.2006.00676.

Miles M.B. \& Huberman A.M. (1994) Qualitative Data Analysis: An Expanded Sourcebook, 2nd edn. Sage, Thousand Oaks CA.

Moran P. (2009) Neglect: Research Evidence to Inform Practice, Action for Children, London UK. http://www.actionforchildren.org.uk (Accessed from 24.03.2012)

Moran P., Ghate D. \& Merwe A. (2004) What works in parenting support? A review of international evidence, Policy Research Bureau, DfES, London.

Murray L., Woolgar M., Murray J. \& Cooper P. (2003) Self-exclusion from health care from women at high risk from post-partum depression. Journal of Public Health Medicine, 25 (2), 131-137. DOI.org/10.1093/pubmed/fdg028

Olds D.L., Sadler L. \& Kitzman H. (2007) Programs for parents of infants and toddlers: Recent evidence from randomized trials. Journal of Child Psychology and Psychiatry, 48 (3-4), 355-391. DOI:10.1111/j.1469-7610.2006.01702

Pattoni L. (2012) Strengths-based Approaches for Working with Individuals, Institute for Research and Innovation in Social Services, IRISS Insights no. 16, Glasgow Scotland.

Peckover S. (2002) Supporting and policing mothers: An analysis of the disciplinary practices of health visiting. Journal of Advanced Nursing, 38 (4), 369-377.

Pitts M. \& Smith A. S. (Eds.) (2007) Researching the Margins: Strategies For Ethical and Rigorous Research with Marginalised Communities. Palgrave Macmillan, Basingstoke UK.

Platt D. (2012). Understanding parental engagement with child welfare services: An integrated model. Child and Family Social Work, 17 (2), 138-148. DOI:10.1046/j.13652648.2002.02197

Robson C. (2002) Real World Research 2nd edn. Blackwell Publishers, Oxford UK.

Roche B., Cowley S., Salt N., Scammell A., Malone M., Savile P., Aikens D., \& Fitzpatrick S. (2005) Reassurance or judgement? Parents' views on the delivery of child health surveillance programmes. Family Practice 22 (5), 507-512. DOI:10.1093/fampra/cmi046

Russell S. \& Drennan V. (2007) Mothers' views of the health-visiting service in the UK: A web-based survey. Community Practitioner, 80, 22-26.

Scott S. \& Dadds M.R. (2009) Practitioner review: When parent training doesn't work: Theory-driven clinical strategies. Journal of Child Psychology and Psychiatry, 50 (12), 1441-1450. DOI:10.1111/j.1469-7610.2009.02189 
Tilley L. \& Woodhouse K. (2011) Is it the end of anonymity as we know it? A critical examination of the ethical principle of anonymity in the context of $21^{\text {st }}$ Century demands on the qualitative researcher. Qualitative Research. 11(2): 197-212.

Warren-Adamson C. (2006) Research review: Family centres: A review of the literature. Child and Family Social Work, 11 (2), 171-182. DOI:10.1111/j.1365-2206.2.2006.00413

Whittaker K.A. \& Cowley S. (2012a) A survey of parental self-efficacy experiences: Maximising potential through health-visiting and universal parenting support. Journal of Clinical Nursing, 21, 3276-3286. DOI:10.1111/j.1365-2702.2012.04074

Whittaker K.A. \& Cowley A. (2012b) An effective programme is not enough: A review of factors associated with poor attendance and engagement with parenting support programmes. Children and Society, 26 (2), 138-149. DOI:10.1111/j.10990860.2010.00333 